\author{
An independent, international science panel would coordinate and highlight research on a pressing topic.
}

T he 2006 review of the economics of climate change, chaired by economist Nicholas Stern, served as a wake-up call to the need to respond to long-term climatic risks. Similarly, the final report of the Economics of Ecosystems and Biodiversity study, due this October, is touted as a 'Stern review for nature'. It will no doubt make a grim read that presents the massive price of biodiversity loss, and the destruction of ecosystems and the services they supply. Organizers of the study - an outcome of the 2007 Potsdam meeting of environment ministers of G8 countries and the five main newly industrializing countries - hope that it, too, will snap policy-makers to attention.

Moves are now afoot to establish a body to review the science and anticipated effects of changes in biodiversity, reminiscent of the Intergovernmental Panel on Climate Change (IPCC). Next week in Busan, South Korea, representatives from governments around the world will decide whether to create such a panel, which currently goes by the unwieldy moniker of the Intergovernmental Science-Policy Platform on Biodiversity and Ecosystem Services (IPBES).

Is the IPCC model appropriate for biodiversity? Whereas climate is driven at the global level, biodiversity change is a more local affair. Backers of the IPBES acknowledge that point; from the outset, the panel will conduct assessments on regional as well as global scales. And whereas the hugely complex challenges posed by climate change can be boiled down to a single indicator for policy-makers and the public - the question of how hot the planet will get - there is no comparably significant single question for biodiversity loss.

Despite these differences, climate change and biodiversity loss share one important attribute: they are real, economically significant phenomena that many would rather ignore. The reports of the IPCC made climate change much harder to ignore. If the IPBES can do the same for biodiversity and ecosystem change, it will be very much worth its proposed annual budget of around US $\$ 12$ million.

Provided it smartens up in response to recent hiccups, the IPCC remains the gold standard for independent scientific assessment on an international level. Its reports are the outputs of a formal, intergovernmental process. Representatives in Busan should do their best to reproduce those attributes to make the IPBES as strong.

To ensure that it can speak to all parties that have an influence on biodiversity, the IPBES should have formal relations not just with the Convention on Biological Diversity, but also with other biodiversity treaties, agencies of the United Nations, international environmental non-governmental organizations, global scientific organizations and the private sector.

So far, the panel has the backing of the UN Environment Programme, which, along with the World Meteorological Organization, oversees the IPCC. To get the input of other sectors beyond the environment ministries,

"The IPBES will provide a much-needed focus on standards and infrastructure for biodiversity science." the IPBES should look for additional patrons. If the UN Food and Agriculture Organization helped to run it, for example, the foodproduction interests of farmers and fishermen are more likely to stand behind its conclusions.

The IPBES will also provide a much-needed focus on standards and infrastructure for biodiversity science. Ecologist Harold Mooney, a leading IPBES advocate at Stanford University in Palo Alto, California, argues that the panel should help to improve and harmonize predictive models of global change. A portion of its budget will no doubt be rightly allocated to scientific capacity-building in developing countries. Gap-analysis reports would provide scientists with a list of relevant information that is needed. The IPBES will undoubtedly have strong links with the Group on Earth Observations Biodiversity Observation Network (GEO BON) - a collaboration of more than 100 governmental and other organizations that already share their data and analyses of biodiversity.

Fed by a stream of high-quality data from GEO BON and coordinated by the activities of the IPBES, biodiversity science should flourish. Regular assessments by the IPBES should help our planet's biota to flourish too.

\section{Education ambivalence}

\section{Academic scientists value teaching as much as research - but universities apparently don't.}

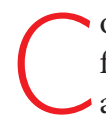

omplaints about the poor quality of science education are a familiar refrain in many countries, as are national anxieties about falling behind the rest of the world. What's not so familiar is that pretty much everyone feels this way. Nature Publishing Group's educational division, Nature Education, last year conducted a survey of 450 university-level science faculty members from more than 30 countries. The first report from that survey, freely available at go.nature.com/5wEKij, focuses on 'postsecondary' university- and college-level education. It finds that more than half of the respondents in Europe, Asia and North America feel that the quality of undergraduate science education in their country is mediocre, poor or very poor.

Despite agreeing that inadequate secondary-school science education is the major problem, respondents concurred on how they could help contribute to a solution: by having professors provide better college-level teaching. Moreover, $77 \%$ of respondents indicated that they considered their teaching responsibilities to be just as important as their research - and 16\% said teaching was more important.

Yet although there was general agreement about the low quality of undergraduate education, a substantial majority of the respondents 